\title{
Folate and Vitamin B6 From Diet and Supplements in Relation to Risk of Coronary Heart Disease Among Women
}

\section{Citation}

Rimm, Eric B., et al. 1998. 'Folate and Vitamin B $<S U B>6</ S U B>$ From Diet and Supplements in Relation to Risk of Coronary Heart Disease Among Women.' JAMA 279, 5: 359. https:// doi.org/10.1001/jama.279.5.359

\section{Permanent link}

http://nrs.harvard.edu/urn-3:HUL.InstRepos:41263087

\section{Terms of Use}

This article was downloaded from Harvard University's DASH repository, and is made available under the terms and conditions applicable to Other Posted Material, as set forth at http:// nrs.harvard.edu/urn-3:HUL.InstRepos:dash.current.terms-of-use\#LAA

\section{Share Your Story}

The Harvard community has made this article openly available. Please share how this access benefits you. Submit a story.

Accessibility 


\title{
Original Contributions
}

\section{Folate and Vitamin $\mathrm{B}_{6}$ From Diet and Supplements in Relation to Risk of Coronary Heart Disease Among Women}

\author{
Eric B. Rimm, ScD; Walter C. Willett, MD, DrPH; Frank B. Hu, MD, PhD; Laura Sampson, MS; \\ Graham A. Colditz, MB, BS, DrPH; JoAnn E. Manson, MD, DrPH; \\ Charles Hennekens, MD, DrPH; Meir J. Stampfer, MD, DrPH
}

Context.-Hyperhomocysteinemia is caused by genetic and lifestyle influences, including low intakes of folate and vitamin $\mathrm{B}_{6}$. However, prospective data relating intake of these vitamins to risk of coronary heart disease (CHD) are not available.

Objective.-To examine intakes of folate and vitamin $\mathrm{B}_{6}$ in relation to the incidence of nonfatal myocardial infarction (MI) and fatal CHD.

Design.-Prospective cohort study.

Setting and Patients. - In 1980, a total of 80082 women from the Nurses' Health Study with no previous history of cardiovascular disease, cancer, hypercholesterolemia, or diabetes completed a detailed food frequency questionnaire from which we derived usual intake of folate and vitamin $B_{6}$.

Main Outcome Measure.--Nonfatal MI and fatal CHD confirmed by World Health Organization criteria.

Results.-During 14 years of follow-up, we documented 658 incident cases of nonfatal $\mathrm{MI}$ and 281 cases of fatal CHD. After controlling for cardiovascular risk factors, including smoking and hypertension and intake of alcohol, fiber, vitamin $\mathrm{E}$, and saturated, polyunsaturated, and trans fat, the relative risks (RRs) of CHD between extreme quintiles were 0.69 (95\% confidence interval [Cl], 0.55-0.87) for folate (median intake, $696 \mu \mathrm{g} / \mathrm{d}$ vs $158 \mu \mathrm{g} / \mathrm{d}$ ) and 0.67 (95\% Cl, 0.53-0.85) for vitamin $\mathrm{B}_{6}$ (median intake, $4.6 \mathrm{mg} / \mathrm{d}$ vs $1.1 \mathrm{mg} / \mathrm{d}$ ). Controlling for the same variables, the RR was 0.55 (95\% Cl, 0.41-0.74) among women in the highest quintile of both folate and vitamin $\mathrm{B}_{6}$ intake compared with the opposite extreme. Risk of CHD was reduced among women who regularly used multiple vitamins $(R R=0.76 ; 95 \% \mathrm{Cl}$, $0.65-0.90$ ), the major source of folate and vitamin $B_{6}$, and after excluding multiple vitamin users, among those with higher dietary intakes of folate and vitamin $\mathrm{B}_{6}$. In a subgroup analysis, compared with nondrinkers, the inverse association between a high-folate diet and CHD was strongest among women who consumed up to 1 alcoholic beverage per day $(\mathrm{RR}=0.69 ; 95 \% \mathrm{Cl}, 0.49-0.97)$ or more than 1 drink per day $(\mathrm{RR}=0.27 ; 95 \% \mathrm{Cl}, 0.13-0.58)$.

Conclusion.-These results suggest that intake of folate and vitamin $\mathrm{B}_{6}$ above the current recommended dietary allowance may be important in the primary prevention of $\mathrm{CHD}$ among women.

JAMA. 1998;279:359-364

From the Departments of Epidemiology (Drs Rimm Willett, Colditz, Manson, Hennekens, and Stampfer) and Nutrition (Drs Rimm, Willett, $\mathrm{Hu}$, and Stampfer and Ms Sampson), Harvard School of Public Health, Boston, Mass; the Channing Laboratory (Drs Rimm, Willett, Colditz, Manson, Hennekens, and Stampfer) and the Division of Preventive Medicine (Drs Manson and Hennekens) Department of Medicine, Brigham and Women's Hospital and Harvard Medical School, Boston, Mass; and the Department of Ambulatory Care and Prevention (Dr Hennekens) Harvard Medical School, Boston, Mass.

Reprints: Eric B. Rimm, ScD, Department of Nutrition, Harvard School of Public Health, 665 Huntington Ave, Boston, MA 02115 (e-mail: eric.rimm@channing.harvard.edu). late and vitamin $\mathrm{B}_{6}$ are important cofactors for metabolism. Supplementation of the diet above the recommended dietary allowance(RDA) with folate alone,,${ }^{4,5}$ or in combination with vitamin $\mathrm{B}_{6}$ and vitamin $\mathrm{B}_{12}$, reduces homocysteine levels. ${ }^{3,6-9}$ The current RDA for folic acid for nonpregnant women is $180 \mu \mathrm{g} / \mathrm{d},{ }^{10}$ and the average dietary intake in this country among adult women is approximately $225 \mu \mathrm{g} / \mathrm{d} .{ }^{11}$ Because of evidence that this level of intake may be insufficient to minimize risk of neural tube defects, and possibly coronary heart disease (CHD), some have urged that the RDA be reset to the earlier level of $400 \mathrm{\mu g} / \mathrm{d} .^{12}$

\section{For editorial comment see p 392.}

Although homocysteine may be atherogenic, it also may be only a marker of folate and vitamin $\mathrm{B}_{6}$ status. Recent epidemiologic evidence suggests that populations with higher plasma levels of folate and pyridoxal 5'-phosphate (PLP, the active form of vitamin $\mathrm{B}_{6}$ ) have lower risk of carotid artery stenosis ${ }^{13}$ and CHD. ${ }^{14-16}$ In 1 retrospective study ${ }^{15}$ of 130 myocardial infarction (MI) cases and 118 controls, folate intake was inversely associated with CHD risk. To our knowledge, this relation has not been prospectively studied. Furthermore, previous studies have not examined the independent effects of folate and vitamin $\mathrm{B}_{6}$ from food or from supplements on risk of CHD, nor have previous studies collected sufficient detail to examine subpopulations of individuals at higher risk of CHD due to factors that may directly or indirectly affect circulating levels of folate (eg, smoking, parental history of MI, and alcohol). Therefore, we examined the relation of intakes of folate and vitamin $\mathrm{B}_{6}$ to risk of CHD among 80082 women enrolled in the Nurses' Health Study and followed prospectively for 14 years (1980-1994). 


\section{METHODS}

\section{The Nurses' Health Study Cohort}

Details of the Nurses' Health Study have been published elsewhere. ${ }^{17}$ Briefly, the cohort was established in 1976 when 121700 female registered nurses aged 30 to 55 years and residing in 11 large US states completed a mailed questionnaire on their medical history and lifestyle. Every 2 years, follow-up questionnaires have been sent to update information on potential risk factors and identify newly diagnosed cases of CHD and other diseases. In 1980, a 61-item food frequency questionnaire (FFQ) was included to assess intake of micronutrients and other components of diet. ${ }^{18}$ In 1984 , the FFQ was expanded to include 116 items. Similar questionnaires were used to update diet in 1986 and 1990.

\section{Semiquantitative FFQs}

A detailed description of the dietary questionnaires and documentation of their reproducibility and validity have been published elsewhere. ${ }^{18-21}$ Briefly, the questionnaire at baseline contained 61 foods that allowed maximum discrimination of macronutrient and micronutrient intake. The 1980 questionnaire also gathered information on brand of cold cereal, use of vitamin supplements, brand and type of multiple vitamin, usual number taken per week, and years of past supplement use. Refinements to the original instrument led to approximately twice the number of foods on revised questionnaires in 1984, 1986, and 1990. On all dietary questionnaires, a commonly used unit or portion size for each food (eg, 1 egg or 1 slice of bread) was specified, and the participant was asked how often on average during the previous year she had consumed that amount of each food. Nine responses were possible, ranging from "never or less than once per month" to "six or more times per day." The intake of nutrients was computed by multiplying the frequency of consumption of each unit of food by the nutrient content of the specified portion. Food composition values for folate, riboflavin, vitamin $\mathrm{B}_{6}$, vitamin $\mathrm{B}_{12}$, methionine, and other nutrients were obtained from the Harvard University Food Composition Database (November 22, 1993) derived from US Department of Agriculture sources ${ }^{22}$ and supplemented with manufacturer information.

In a detailed validation study, we compared nutrients derived from the 61item baseline questionnaire with those from four 1-week diet records collected at approximately 3-month intervals and found that the FFQ can provide a reasonable measure of dietary intake of micronutrients among female nurses. ${ }^{18,21}$
For example, for vitamin $B_{6}$, we found a correlation of 0.58 ( 0.54 for vitamin $\mathrm{B}_{6}$ from foods only) between energy-adjusted nutrient intake derived from the questionnaire and that from the average of four 1-week diet records. ${ }^{18}$

As further validation of the dietary instrument, we, ${ }^{23}$ and others, ${ }^{24,25}$ have found that the FFQ predicts circulating levels of folate and vitamin $\mathrm{B}_{6}$. In the Framingham Heart Study, intake calculated from the $\mathrm{FFQ}^{24,25}$ predicted plasma folate $(r=0.56)$, plasma vitamin $\mathrm{B}_{6}$ (measured as PLP) $(r=0.51),{ }^{24}$ and homocysteine levels. ${ }^{25}$

\section{Population}

After up to 4 mailings, 98462 women returned the 1980 diet questionnaire. A priori, we excluded women who had implausibly high $(>14700 \mathrm{~kJ} / \mathrm{d}$ [3500 kcal/d]) or low $(<2100 \mathrm{~kJ} / \mathrm{d}[500 \mathrm{kcal} / \mathrm{d}])$ total energy intake or those who left 10 or more items blank. We further excluded women with previously diagnosed cancer $(n=3526)$ and cardiovascular disease (ie, angina, MI, stroke, tachycardia, transient ischemic attack; $n=1821$ ). In addition, women reporting hypercholesterolemia $(n=4122)$ or diabetes $(n=1812)$ were excluded because these conditions are associated with risk of $\mathrm{CHD}$ and these women might tend to change their diet and lifestyle habits after diagnosis. The final 1980 baseline population consisted of 80082 women.

\section{Outcome}

We defined the primary outcome of CHD as documented symptomatic nonfatal MI or fatal CHD occurring after the return of the 1980 questionnaire but before June 1, 1994. We requested permission to review medical records from women who reported a nonfatal MI on a follow-up questionnaire. The records were reviewed by study physicians blinded to the exposure status. We used the World Health Organization criteria for MI; confirmation required symptoms plus either diagnostic electrocardiographic changes or elevated cardiac enzymes. Myocardial infarctions that required hospital admission and for which confirmatory information was obtained by interview or letter, but for which no medical records were available, were designated as "probable." We included all "confirmed" and "probable" cases in our analyses because results were not substantially different after excluding $17 \%$ of cases defined as "probable."

We were notified of most deaths by the next of kin or the post office. Every 2 years we also search the National Death Index for nonrespondents to biennial questionnaires. We estimate that follow-up for deaths is over $98 \%$ com- plete. ${ }^{26}$ Fatal CHD was defined as fatal MI if confirmed by hospital records or autopsy, or if CHD was listed as the primary cause on the death certificate and evidence of previous CHD was available. Information from death certificate alone was not sufficient for the confirmation of CHD.

\section{Data Analysis}

All nutrients were energy-adjusted using the residual method.21,27 Energy adjustment is based on the a priori biologic considerations that a larger, more physically active person will require a higher caloric intake, which will also be associated with a higher absolute intake of all nutrients. Therefore, by adjusting for energy intake, we examined the composition of the diet, accounting for differences in energy requirements among individuals. The residuals were standardized to the predicted nutrient intake of a women consuming $6720 \mathrm{~kJ} / \mathrm{d}$ $(1600 \mathrm{kcal} / \mathrm{d})$, the average total energy intake among women responding to the 1980 dietary questionnaire. After energy adjustment, quintiles were created for each nutrient. Person-time for each participant was calculated from the date of return of the 1980 questionnaire to the date of first CHD event, death, or June 1, 1994. Women who reported cardiovascular disease or cancer on previous questionnaires were excluded from subsequent follow-up; thus, each participant could contribute only 1 end point, and the cohort at risk included only those who remained free from a cardiovascular and cancer end point at the beginning of each 2-year follow-up interval.

We calculated incidence rates as the number of events divided by the persontime of follow-up in each quintile. The relative risk $(\mathrm{RR})$ was computed as the rate in a specific quintile of a micronutrient divided by that in the lowest quintile, with adjustment for 5-year age categories. In all multivariate analyses, we calculated the odds ratio of CHD (as an estimate of the RR) for quintiles of baseline (1980) nutrients controlling for age; time period; smoking; body mass index (a measure of weight in kilograms divided by the square of height in meters); postmenopausal hormones; aspirin; vitamin E supplements; exercise; hypertension; parental history of CHD; and intake of polyunsaturated, saturated, and trans fat, fiber, and alcohol. The main analyses were conducted as a pooled logistic regression ${ }^{28}$ using baseline nutrients with covariates updated using data from each biennial follow-up. In secondary analyses, incidence of $\mathrm{CHD}$ was related to the cumulative average of nutrient intake from dietary questionnaires administered in 1980, 1984, 1986, 
and 1990. Incident cases documented between each 2- or 4-year diet questionnaire cycle were examined in relation to the average diet calculated from all the preceding diet measures. Since change in diet after development of intermediate conditions such as angina, hypercholesterolemia, and diabetes may confound the exposure-disease association, we stopped updating diet and covariates at the beginning of the time interval during which individuals developed those intermediate end points.

\section{RESULTS}

During 14 years of follow-up, we identified 658 incident cases of nonfatal MI and 281 cases of fatal CHD. Based on the assessment of average diet, the largest contributors (in absolute percentage) to the overall intake of folate were multiple vitamins (26\%), cold cereal (8\%), orange juice $(8 \%)$, lettuce $(7.5 \%)$, eggs $(3 \%)$, broccoli $(2.5 \%)$, and spinach (2\%). Although women with higher folate intake were older and had a higher prevalence of hypertension, they generally weighed less, were less likely to smoke, and ate a diet higher in fiber and lower in saturated fat, polyunsaturated fat, and trans fat (Table 1).

Using the baseline 1980 measure of dietary folate to classify women into quintiles of intake, the age-adjusted RR of CHD was 0.53 (95\% confidence interval [CI], 0.43-0.65) comparing women in the highest and lowest quintiles (Table 2). In multivariate models of folate and CHD, smoking and use of vitamin E supplements were the strongest confounders. The RR for folate was 0.61 (95\% CI, 0.49$0.75)$ after adding smoking to the model and was further attenuated to 0.65 (95\% CI, 0.53-0.80) after controlling for current use of vitamin E supplements. After controlling for other cardiovascular risk factors, including dietary variables, the final multivariate RR (Table 2) was only slightly further attenuated $(R R=0.69$; 95\% CI, 0.55-0.87). In an analysis of the overall trend we found an RR of $0.89(95 \%$ CI, 0.82-0.96) for each 200- $\mu \mathrm{g}$ increase in folate. Furthermore, to assess whether the dose-response relationship for folate extended beyond the RDA of $180 \mu \mathrm{g} / \mathrm{d}$, we excluded all women at or below the RDA and still found a significant decrease in risk of CHD for each 200 - $\mu \mathrm{g}$ increase in folate $(\mathrm{RR}=0.91 ; 95 \% \mathrm{CI}, 0.84-0.99)$. When intake of riboflavin, vitamin $\mathrm{B}_{12}$, and methionine were added to the models, they did not appreciably alter the RR of folate (RRs of CHD between extreme quintiles: for riboflavin, $\mathrm{RR}=0.99$ [95\% CI, 0.67-1.48]; for vitamin $\mathrm{B}_{12}, \mathrm{RR}=1.09$ [95\% CI, 0.82-1.44]; and for methionine, $\mathrm{RR}=0.82[95 \% \mathrm{CI}, 0.65-1.03])$. Therefore, these nutrients were not included in sub-

Table 1.-Baseline (1980) Diet and Lifestyle Characteristics by Quintiles of Total Energy-Adjusted Folate Intake Among 80082 Women Enrolled in the Nurses' Health Study*

\begin{tabular}{|c|c|c|c|c|c|}
\hline & \multicolumn{5}{|c|}{ Folate Quintile } \\
\hline & $\begin{array}{c}1 \\
(<190 \mu \mathrm{g})\end{array}$ & $\begin{array}{c}2 \\
(190-244 \mu g)\end{array}$ & $\begin{array}{c}3 \\
(245-318 \mu g)\end{array}$ & $\begin{array}{c}4 \\
(319-544 \mu g)\end{array}$ & $\begin{array}{c}5 \\
(\geq 545 \mu \mathrm{g})\end{array}$ \\
\hline Folate, $\mu \mathrm{g} / \mathrm{d}$ & 153 & 217 & 278 & 409 & 774 \\
\hline Age, y & 44.7 & 45.7 & 46.4 & 46.3 & 46.3 \\
\hline Body mass index, $\mathrm{kg} / \mathrm{m}^{2}$ & 24.3 & 24.4 & 24.4 & 24.1 & 23.9 \\
\hline Current smokers, $\%$ & 36.9 & 29.6 & 26.4 & 24.8 & 24.6 \\
\hline Multiple vitamins, \% & 7.7 & 10.6 & 14.7 & 43.7 & 94.5 \\
\hline Vitamin E supplements, \% & 5.9 & 6.9 & 8.9 & 14.3 & 27.5 \\
\hline Postmenopausal hormones, \% & 6.0 & 5.8 & 6.3 & 6.6 & 7.4 \\
\hline Regular exercise, \%† & 35.0 & 42.2 & 47.1 & 50.9 & 50.8 \\
\hline Hypertension, \% & 13.1 & 14.0 & 14.7 & 14.2 & 14.1 \\
\hline Parental history of $\mathrm{CHD}, \% \ddagger$ & 19.8 & 20.0 & 20.3 & 19.8 & 19.7 \\
\hline $\begin{array}{l}\text { Average intake of } \\
\text { Vitamin } \mathrm{B}_{6}, \mathrm{mg} / \mathrm{d}\end{array}$ & 1.5 & 1.9 & 2.2 & 3.3 & 5.9 \\
\hline Vitamin $B_{12}, \mu \mathrm{g} / \mathrm{d}$ & 5.5 & 6.1 & 6.8 & 9.3 & 17.2 \\
\hline Vitamin $\mathrm{B}_{2}, \mathrm{mg} / \mathrm{d}$ & 2.2 & 2.6 & 2.9 & 3.6 & 5.5 \\
\hline Methionine, $\mathrm{g} / \mathrm{d}$ & 1.7 & 1.8 & 1.9 & 1.9 & 1.9 \\
\hline Saturated fat, $\mathrm{g} / \mathrm{d}$ & 31.1 & 29.0 & 27.2 & 26.1 & 26.8 \\
\hline Polyunsaturated fat, $\mathrm{g} / \mathrm{d}$ & 10.0 & 9.6 & 9.2 & 8.9 & 9.0 \\
\hline Trans fat, $\mathrm{g} / \mathrm{d}$ & 4.6 & 4.2 & 3.9 & 3.6 & 3.7 \\
\hline Fiber, g/d & 10.2 & 12.6 & 14.6 & 15.8 & 14.9 \\
\hline Alcohol, g/d & 6.9 & 6.8 & 6.6 & 6.5 & 6.5 \\
\hline
\end{tabular}

*Means for each quintile are directly age-standardized using the age distribution of the 80082 women eligible for analyses.

tRegular exercise is defined as vigorous exercise 1 or more times per week

$\ddagger$ arental history of coronary heart disease (CHD) is assigned to women who reported a myocardial infarction in either parent before the age of 65 years.

sequent analyses. The multivariate RRs for folate in Table 2 were not appreciably altered after further controlling for intake of carotene, magnesium, iron, or monounsaturated fat. The reduction in risk of CHD associated with a higher folate intake was similar when we used the updated cumulative average as a measure of intake rather than only the baseline values and when we used either nonfatal MI or fatal CHD as the outcome.

In more detailed analyses, we examined the independent associations for folate from diet and from supplemental intake. In the same multivariate model noted in Table 2 we simultaneously included folate from both sources; a diet high in folate from food or supplements conferred a reduction in risk of CHD (for food, $\mathrm{RR}=0.78$ [95\% CI, 0.61-1.01]; quintile 5 , median $379 \mu \mathrm{g} / \mathrm{d}$ vs quintile 1 , median $151 \mu \mathrm{g} / \mathrm{d}$; for supplements, $R R=0.76$ [95\% CI, 0.59-0.98]; 400-1000 $\mathrm{kg} / \mathrm{d}$ vs no supplements). The RR for a diet high in folate was virtually identical after excluding the $33.7 \%$ of women who reported use of vitamin supplements.

We conducted similar analyses for vitamin $B_{6}$ as to those presented above for folate. As with folate, vitamin supplements were by far the largest contributor to total vitamin $\mathrm{B}_{6}$ intake. Among the $66.3 \%$ of women not taking a multiple vitamin or other supplements containing vitamin $\mathrm{B}_{6}$, the leading contributors to intake were beef (14\%), cold breakfast cereal $(9 \%)$, potatoes $(9 \%)$, bananas
(8.5\%), chicken (7\%), milk (5\%), and tuna fish $(3.5 \%)$. Compared with women in the lowest quintile of vitamin $\mathrm{B}_{6}$ intake, the age-adjusted RR of CHD was $0.49(95 \%$ CI, 0.40-0.61) among women in the highest quintile. As with folate, the 2 strongest confounders were smoking and use of vitamin E supplements. The final multivariate $R R$ was 0.67 (95\% CI, 0.53-0.85) after controlling for measured predictors of CHD (Table 2). In an analysis of the overall trend we found an RR of 0.83 (95\% CI, 0.74-0.93) for each 2-mg increase in vitamin $\mathrm{B}_{6}$. Although we had substantially fewer cases $(n=458)$ after excluding all women at or below the RDA of $1.6 \mathrm{mg} / \mathrm{d}$, the RR for each $2-\mathrm{mg}$ increase in vitamin $B_{6}$ intake above the RDA was still suggestive of a reduction in risk of $\mathrm{CHD}(\mathrm{RR}=0.90 ; 95 \% \mathrm{CI}, 0.79$ 1.03). In the model that simultaneously assessed the independent associations for vitamin $B_{6}$ from food or supplement sources, the inverse association for supplemental intake $(\mathrm{RR}=0.75 ; 95 \% \mathrm{CI}$, 0.62-0.92; for $2-10 \mathrm{mg} / \mathrm{d}$ of supplements vs no supplements) was slightly stronger than for intake from foods $(\mathrm{RR}=0.85$; 95\% CI, 0.68-1.07; between quintile 5 [median $2.3 \mathrm{mg} / \mathrm{d}$ ] and quintile 1 [median $1.1 \mathrm{mg} / \mathrm{d}])$. However, in this model the range in vitamin $\mathrm{B}_{6}$ was much broader for intake of supplements than for foods. The model that incorporated vitamin $\mathrm{B}_{6}$ assessed from follow-up questionnaires yielded similar results as the multivariate with only baseline dietary measures. 
Table 2.-Relative Risk (RR) and 95\% Confidence Intervals (Cls) of Coronary Heart Disease (CHD) (Nonfatal Myocardial Infarction and Fatal CHD) by Quintiles of Total Energy-Adjusted Folate and Vitamin B ${ }_{6}$ Intake Among 80082 Women Enrolled in the Nurses' Health Study (1980-1994)

\begin{tabular}{|c|c|c|c|c|c|c|}
\hline & \multicolumn{5}{|c|}{ Quintiles } & \multirow{2}{*}{$\begin{array}{l}P \text { for } \\
\text { Trend }\end{array}$} \\
\hline & 1 & 2 & 3 & 4 & 5 & \\
\hline Folate, median, $\mu \mathrm{g} / \mathrm{d}$ & 158 & 217 & 276 & 393 & 696 & \\
\hline Cases, No. & 237 & 197 & 197 & 168 & 140 & \\
\hline Age-adjusted RR $(95 \% \mathrm{Cl})$ & 1.0 & $0.76(0.63-0.91)$ & $0.72(0.60-0.87)$ & $0.61(0.50-0.75)$ & $0.53(0.43-0.65)$ & $<.001$ \\
\hline Multivariate RR $(95 \% \mathrm{Cl})^{*}$ & 1.0 & $0.86(0.71-1.05)$ & $0.86(0.70-1.06)$ & $0.78(0.63-0.98)$ & $0.69(0.55-0.87)$ & .003 \\
\hline Vitamin $\mathrm{B}_{6}, \mathrm{mg} / \mathrm{d}$ (median) & 1.1 & 1.3 & 1.7 & 2.7 & 4.6 & \\
\hline Cases & 216 & 210 & 207 & 175 & 131 & \\
\hline Age-adjusted RR $(95 \% \mathrm{Cl})$ & 1.0 & $0.80(0.66-0.97)$ & $0.70(0.50-0.85)$ & $0.68(0.55-0.82)$ & $0.49(0.40-0.61)$ & $<.001$ \\
\hline Multivariate RR $(95 \% \mathrm{Cl})^{*}$ & 1.0 & $0.92(0.76-1.12)$ & $0.86(0.70-1.05)$ & $0.88(0.76-1.10)$ & $0.67(0.53-0.85)$ & .002 \\
\hline
\end{tabular}

*Multivariate adjustment for age (5-year categories); time period; body mass index (5 categories); smoking (never, past, and 1-14, 15-24, and $\geq 25$ cigarettes per day); menopausal status (premenopausal, postmenopausal without hormone replacement, postmenopausal with current hormone replacement); aspirin; vitamin $\mathrm{E}$ supplements; physical activity; hypertension; parental history of myocardial infarction before age 65 years; alcohol ( 5 categories); and quintiles of fiber, alcohol, and saturated, polyunsaturated, and trans fat.

Table 3.-Relative Risk (RR) and 95\% Confidence Interval (Cls) of Coronary Heart Disease (CHD) (Nonfatal Myocardial Infarction and Fatal CHD) for Users of Multiple Vitamin Supplements in 1980 Among 80082 Women Enrolled in the Nurses' Health Study (1980-1994)

\begin{tabular}{|c|c|c|c|}
\hline & \multirow[b]{2}{*}{ Nonusers } & \multicolumn{2}{|c|}{ Current Users* } \\
\hline & & $\begin{array}{c}1-3 \\
\text { Pills/wk }\end{array}$ & $\begin{array}{c}4-7 \\
\text { Pills/wk }\end{array}$ \\
\hline Cases, No. & 702 & 31 & 184 \\
\hline Person-years & 716913 & 42685 & 272435 \\
\hline Age-adjusted RR & 1.0 (Referent) & $0.82(0.57-1.17)$ & $0.67(0.57-0.79)$ \\
\hline Multivariate RR† & 1.0 (Referent) & $0.97(0.68-1.40)$ & $0.76(0.65-0.90)$ \\
\hline
\end{tabular}

*Twenty-two cases (2\%) were not included in the current user category because information on numbers of pills per week was missing or well above 1 per day.

†Adjusted for same variables as in Table 2 .

The reduction in risk associated with a high intake of vitamin $\mathrm{B}_{6}$ was similar for nonfatal MI or fatal CHD.

Intakes of folate and vitamin $\mathrm{B}_{6}$ were highly correlated (Spearman $r=0.77$ ) largely because multiple vitamins and fortified breakfast cereals were major sources of both; this correlation somewhat limited our ability to assess their independent effects. Therefore, we examined risk of CHD among women with high intakes of both of these vitamins. For those in the highest quintile of both total folate and total vitamin $\mathrm{B}_{6}$ compared with women in the lowest quintile of both nutrients the multivariate $\mathrm{RR}$ of CHD was 0.55 (95\% CI, 0.41-0.74). The $\mathrm{RR}$ was similar $(\mathrm{RR}=0.51 ; 95 \% \mathrm{CI}, 0.33$ 0.77) after excluding women with supplemental intake of either micronutrient during the follow-up period.

Because most of the supplemental intake of folate and vitamin $\mathrm{B}_{6}$ came from multiple vitamins, we further examined the risk of CHD among users and nonusers (Table 3). Compared with women not taking a multiple vitamin supplement at baseline, the age-adjusted RR of CHD was 0.69 (95\% CI, 0.59-0.81) among women taking a supplement at least every other day. The association was only modestly attenuated $(\mathrm{RR}=0.76$; 95\% CI, 0.65 0.90 ) after accounting for other known risk factors (Table 3). Women who reported taking at least 4 multiple vitamin pills a week for 5 or more years had the lowest risk of $\mathrm{CHD}(\mathrm{RR}=0.71 ; 95 \% \mathrm{CI}$, $0.56-0.90$ ). The $2 \%$ of women who reported taking more than 1 multiple vitamin per day did not experience a reduction in CHD (RR $=1.19 ; 95 \%$ CI, 0.78-1.83).

We conducted further analyses examining combinations of factors that may influence folate or homocysteine levels. We divided the cohort into 3 groups based on average alcohol consumption (abstainers, $0.1-14.9 \mathrm{~g} / \mathrm{d}$, and $\geq 15.0 \mathrm{~g} / \mathrm{d}$ ). These levels of consumption are approximately equivalent to 0 , up to 1 , and more than 1 drink per day, respectively. The inverse relation between folate intake and risk of CHD was stronger with each increasing level of alcohol consumption. Among women consuming up to 1 drink per day, the RR of CHD, comparing the highest with lowest quintiles of folate, was 0.69 (95\% CI, 0.49-0.97) and among those consuming more than 1 drink per day, the comparable RR was 0.27 (95\% CI, 0.13-0.58). We also conducted a separate analysis in the whole study population using a multivariate model that included indicator variables for each combination of folate and alcohol. Compared with women who were in the lowest quintile of dietary folate and who abstained from alcohol, the RR of CHD among women in the highest quintile of folate was 0.55 (95\% CI, 0.40-0.77) at alcohol levels up to 1 drink a day and 0.22 (95\% CI, 0.11-0.44) among those drinking at least 1 drink a day (Figure). The reduction in risk of CHD associated with a high-folate diet was somewhat stronger among women with a parental history of CHD before 65 years of age $(\mathrm{RR}=0.57 ; 95 \% \mathrm{CI}, 0.37-0.87)$ than those without $(\mathrm{RR}=0.74 ; 95 \% \mathrm{CI}, 0.57-0.97)$ and among women who were current smokers at baseline $(\mathrm{RR}=0.55 ; 95 \% \mathrm{CI}$, 0.39-0.77) than among nonsmokers $(\mathrm{RR}=0.87 ; 95 \% \mathrm{CI}, 0.64-1.20)$. The RR between extreme quintiles of vitamin $\mathrm{B}_{6}$ were not appreciably different across levels of alcohol consumption, smoking, or family history of CHD.

\section{COMMENT}

During 14 years of follow-up of this large prospective cohort study of women, we found graded associations between higher intakes of folate and vita$\min \mathrm{B}_{6}$ and lower risk of CHD. For folate, lower risks were seen for higher intake from either food or supplement sources and for intake well above the current RDA of $180 \mu \mathrm{g} / \mathrm{d}$. For vitamin $\mathrm{B}_{6}$, the risk was lowest with higher intake of food and supplement sources combined. Risk of CHD was lowest among women with the highest intake of both folate and vitamin $\mathrm{B}_{6}$. In exploratory analyses of high- and low-risk subgroups, we found the strongest apparent benefit of a highfolate diet among women who consumed alcohol. Our main findings are consistent with the experimental evidence linking higher intake of folate and vitamin $\mathrm{B}_{6}$ with lower homocysteine levels ${ }^{6-9}$ and with the observational evidence suggesting a strong association between elevated homocysteine levels and cardiovascular disease ${ }^{3,29}$; however, we cannot exclude the possibility that homocysteine may only be a marker of folate status and other unknown mechanisms could explain the lower rates of CHD among women with higher intakes of folate and vitamin $\mathrm{B}_{6}$. For example, folate-depleted diets may be prothrombotic. ${ }^{30}$

Because the data we collected are observational, we evaluated whether the 
association with folate could be explained by other healthy lifestyle practices among women in the highest quintile of folate intake. For several variables, such as smoking and use of vitamin E supplements, women in the highest quintile of folate had a lower risk profile (Table 1). Controlling for these factors attenuated the age-adjusted $R R$ from 0.53 (95\% CI, 0.43-0.65) to 0.69 (95\% CI, 0.53-0.85) (Table 2). However, several lines of evidence suggest that this inverse association for folate is not due to further bias or confounding. First, if the self-selection of the healthiest individuals into the highest quintile of folate were to explain our results, we would expect several other micronutrients found in supplements and "healthy diets" also to be related to lower risk. However, we did not find inverse associations for other such micronutrients (eg, riboflavin, vitamin $\mathrm{B}_{12}$, and vitamin $\mathrm{C}^{31}$ ). Second, our data suggest a graded inverse association between CHD and increasing intake of folate regardless of folate source. Finally, the magnitude of the inverse association for folate is consistent with our parallel study among male health professionals $^{32}$ and with the physiologic effects of folate on lowering of homocysteine levels. ${ }^{3}$ From calculations by Boushey et $\mathrm{al}^{3}$ and Tucker et $\mathrm{al}^{25}$ increasing folate intake by $100 \mathrm{\mu g} / \mathrm{d}$ would lower homocysteine levels by $6 \%$ and risk of CHD by approximately $5 \%$. Each $100 \mu \mathrm{g} / \mathrm{d}$ increase in folate in our population was associated with a $5.8 \%$ (95\% CI, 2\%-9\%) lower risk of CHD.

Homocysteine may increase risk of CHD through direct toxicity to endothelial cells, increased coagulation, decreased endothelial reactivity, and stimulation of smooth muscle cell proliferation. ${ }^{33-36}$ Higher levels of homocysteine have been observed among patients with periphera $\mathrm{l}^{37,38}$ and cerebral vascular occlusion ${ }^{39,40}$ and coronary disease. ${ }^{3}$ Although the positive association is graded between levels of homocysteine and degree of carotid artery stenosis $^{13}$ and CHD, ${ }^{3,29,41}$ the association between dietary folate and CHD may not be linear since the association between folate and homocysteine appears to plateau between 400 $\mu \mathrm{g} / \mathrm{d}$ and $1 \mathrm{mg} / \mathrm{d}^{3,24-25}$ Within the range of folate intake in this population (10th percentile of $150 \mu \mathrm{g} / \mathrm{d}$ and $90 \mathrm{th}$ percentile of $700 \mu \mathrm{g} / \mathrm{d}$ ), our results suggest a linear decline in risk of CHD. We were not able to examine benefits of supplementation above $1 \mathrm{mg} / \mathrm{d}$.

Elevated homocysteine levels after a methionine load and fasting homocysteine levels may be independent predictors of CHD. ${ }^{3,15,42}$ Recent evidence suggests that vitamin $\mathrm{B}_{6}$ is generally more effective at lowering homocysteine levels after methionine load, ${ }^{43,44}$ and folate

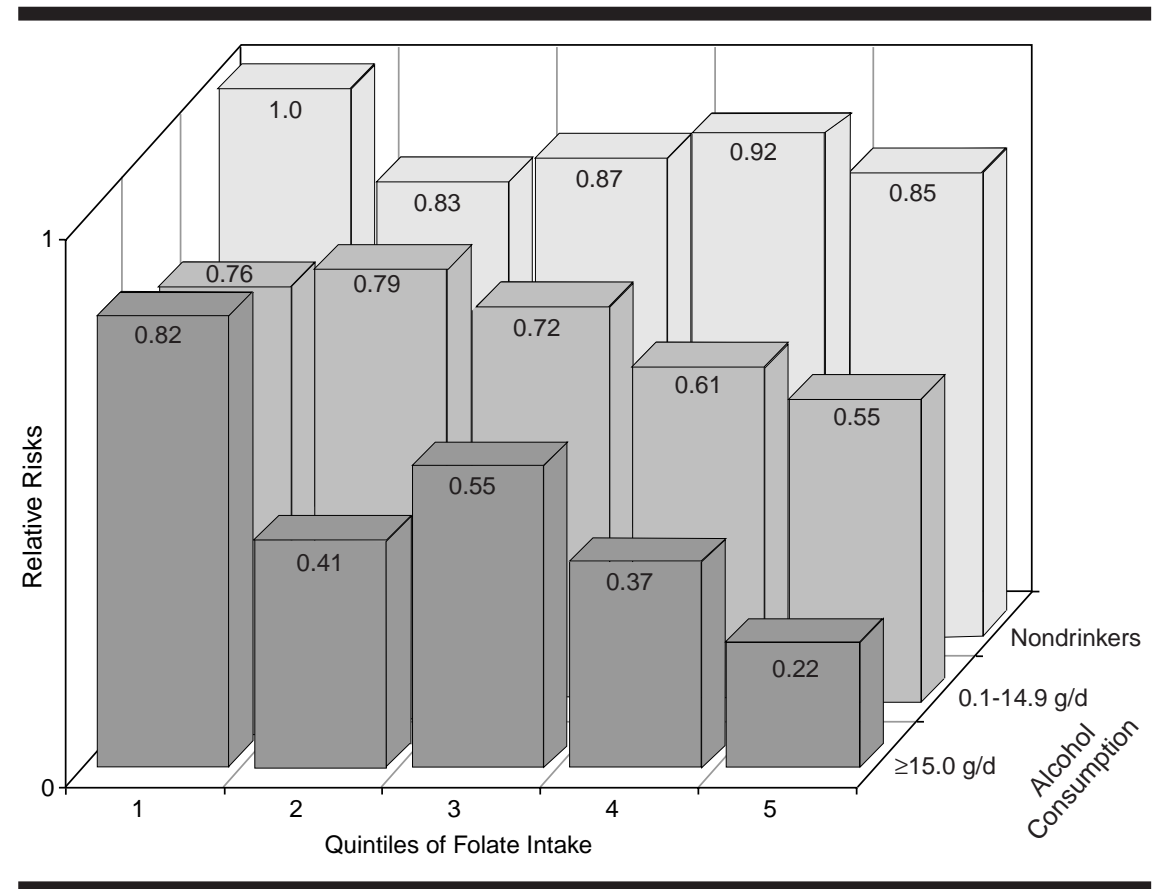

Relative risk of coronary heart disease (nonfatal myocardial infarction and fatal coronary heart disease) by quintiles of energy-adjusted folate across levels of alcohol consumption among 80082 women in the Nurses' Health Study. Women in the lowest quintile of folate who did not drink alcohol were the reference category.

more effective at lowering fasting homocysteine levels. Our results of a maximum benefit among women in the highest quintile of both folate and vitamin $\mathrm{B}_{6}$ $(\mathrm{RR}=0.57 ; 95 \% \mathrm{CI}, 0.40-0.82)$ are consistent with independent effects of these vitamins in lowering homocysteine levels and suggest that maximum benefit is obtained at optimal levels of both. Randomized trials in secondary and primary prevention are needed to test their independent effects. ${ }^{45}$ Although dietary $\mathrm{B}_{12}$ also may lower homocysteine level, plasma $B_{12}$ levels are influenced more by absorption than intake, thus the lack of association between extreme quintiles of dietary vitamin $B_{12}(R R=1.09 ; 95 \% C I$, 0.82-1.44) and risk of CHD is expected.

The stronger inverse association between folate and CHD among women who consumed alcohol (Figure) merits further exploration since several subgroup analyses were conducted. At moderate levels of alcohol consumption, oxidation of acetaldehyde from ethanol metabolism can inactivate folate. ${ }^{46} \mathrm{Fur}$ thermore, acetaldehyde binds and inactivates methionine synthase, ${ }^{47}$ the enzyme responsible for the folate-dependent remethylation of homocysteine to methionine. Therefore, we would expect that the cardiovascular benefits of moderate alcohol consumption ${ }^{48}$ may be partially offset unless women have high folate intake.

In conclusion, in this population of women, higher intakes of folate from food or supplements, alone or in combination with vitamin $\mathrm{B}_{6}$, are associated with substantially lower risk of CHD among women. Our results corroborate and extend recent studies, ${ }^{14-16,49}$ showing lower risk of coronary disease in individuals with higher plasma folate and plasma vitamin $\mathrm{B}_{6}$ levels. Even though in this population of US women average intakes of folate $(366 \mu \mathrm{g} / \mathrm{d}$; median $=277 \mu \mathrm{g} / \mathrm{d})$ and vitamin $\mathrm{B}_{6}(3.0 \mathrm{mg} /$ $\mathrm{d}$; median $=1.7 \mathrm{mg} / \mathrm{d}$ ) were well above those from national averages $(224 \mu \mathrm{g} / \mathrm{d}$ for folate and $1.51 \mathrm{mg} / \mathrm{d}$ for vitamin $\left.\mathrm{B}_{6}\right),{ }^{11}$ we still found a graded reduction in risk with higher intake. The lowest risk was among women with intake of folate above $400 \mu \mathrm{g} / \mathrm{d}$ and vitamin $B_{6}$ above $3 \mathrm{mg} / \mathrm{d}$. Therefore, the current RDA for folate of $180 \mu \mathrm{g} / \mathrm{d}$ and for vitamin $B_{6}$ of $1.6 \mathrm{mg} / \mathrm{d}$ deemed sufficient to prevent deficiency among nonpregnant women ${ }^{10}$ may not be sufficient to minimize risk of coronary disease. Furthermore, for folate, it is estimated that $88 \%$ to $90 \%$ of the population has dietary intakes below $400 \mathrm{\mu g} / \mathrm{d}^{11,50}$ and that the recently implemented policy of folate supplementation of $140 \mu \mathrm{g}$ per $100 \mathrm{~g}$ of grain products in US food supplies may only increase average intakes by $100 \mathrm{\mu g} / \mathrm{d},{ }^{51}$ and less if currently fortified foods are required to reduce fortification levels. ${ }^{52}$ Even after fortification, only $25 \%$ of adult women will have dietary folate intakes above $400 \mu \mathrm{g} / \mathrm{d}$. Our results suggest that any widespread increase in folate intake will have a favorable impact on $\mathrm{CHD}$ rates, but that maximum benefit would be achieved at folate intake of at least $400 \mu \mathrm{g} / \mathrm{d}$. 
This study was supported by research grants HL 34594 and CA 40356 from the National Institutes of Health.

We thank Frank Speizer, MD, the principal investigator of the Nurses' Health Study, for his invaluable contribution to the study and the participants of the Nurses' Health Study for their continued cooperation and participation. We are also indebted to Karen Corsano, Mark Snyder, and Steve Stuart for computer assistance and Adam Summerfield, Jill Arnold, Barbara Egan, and Lisa Dunn for their assistance with compiling the data and preparing the manuscript.

\section{References}

1. McCully KS. Vascular pathology of homocysteinemia: implications for pathogenesis of arteriosclerosis. Am J Pathol. 1969;56:111-128.

2. Mudd SH, Finkelstein JD, Irreverre F, Laster L. Homocystinuria: an enzymatic defect. Science. 1964 143:1443-1445.

3. Boushey CJ, Beresford SAA, Omenn GS, Motulsky AG. A quantitative assessment of plasma homocysteine as a risk factor for vascular disease probable benefits of increasing folic acid intakes. JAMA. 1995;274:1049-1057.

4. Brattstrom LE, Israelsson B, Jeppsson JO, Hultberg BL. Folic acid: an innocuous means to reduce plasma homocyst(e)ine. Scand J Clin Lab Invest. 1988;48:215-221.

5. Brattstrom L, Israelsson B, Norrving B, et al Impaired homocysteine metabolism in early-onset cerebral and peripheral occlusive arterial disease: effects of pyridoxine and folic acid treatment. Ath erosclerosis. 1990;81:51-60.

6. Jacob RA, Wu M, Henning SM, Swendseid ME. Homocysteine increases as folate decreases in plasma of healthy men during short-term dietary folate and methyl group restriction. $J$ Nutr. 1994; 124:1072-1080.

7. Naurath HJ, Joosten E, Riezler R, Stabler SP, Allen RH, Lindenbaum J. Effects of vitamin B-12, folate, and vitamin B-6 supplements in elderly people with normal serum vitamin concentrations. Lancet. 1995;346:85-89.

8. O'Keefe CA, Bailey LB, Thomas EA, et al. Controlled dietary folate affects folate status in nonpregnant women. $J$ Nutr. 1995;125:2717-2725.

9. Ubbink JB, Vermaak WJH, van der Merwe A Becker PJ, Delport R, Potgieter HC. Vitamin requirements for the treatment of hyperhomocysteinemia in humans. J Nutr. 1994;124:1927-1933.

10. Food and Nutrition Board. Recommended Dietary Allowances. 10th revised ed. Washington, DC National Academy of Sciences; 1989 .

11. Wilson JW, Enns CW, Goldman KS, et al. Data tables: combined results from USDA's 1994 and 1995 Continuing Survey of Food Intakes by Individuals and 1994 and 1995 Diet and Health Knowledge Survey. ARS Food Surveys Research Group. Available at: http://www.barc.usda.gov/bhnrc/foodsurvey/ home.htm (under "Releases"). Accessed June 1997. 12. Oakley GP Jr. Let's increase folic acid fortification and include vitamin B-12. Am J Clin Nutr. 1997; 65:1889-1890.

13. Selhub J, Jacques PF, Bostom AG, et al. Association between plasma homocysteine concentrations and extracranial carotid-artery stenosis. N Engl J Med. 1995;332:286-291.

14. Morrison HI, Schaubel D, Desmeules M, Wigle DT. Serum folate and risk of fatal coronary heart disease. JAMA. 1996;275:1893-1896

15. Verhoef P, Stampfer MJ, Buring JE, et al. Homocysteine metabolism and risk of myocardial in- farction: relation with vitamins $\mathrm{B} 6, \mathrm{~B} 12$, and folate. Am J Epidemiol. 1996;143:845-859.

16. Chasan-Taber L, Selhub J, Rosenberg IH, et al. A prospective study of folate and vitamin $\mathrm{B}_{6}$ and risk of myocardial infarction in US physicians. $J$ Am Coll Nutr. 1996;15:136-143.

17. Willett WC, Stampfer MJ, Colditz GA, Rosner BA, Hennekens CH, Speizer FE. Dietary fat and the risk of breast cancer. N Engl J Med. 1987;316:22-28. 18. Willett WC, Sampson L, Stampfer MJ, et al. Reproducibility and validity of a semiquantitative food frequency questionnaire. Am J Epidemiol. 1985;122:51-65.

19. Willett WC, Stampfer MJ, Underwood BA, Speizer FE, Rosner B, Hennekens CH. Validation of a dietary questionnaire with plasma carotenoid and alpha-tocopherol levels. Am J Clin Nutr. 1983 38:631-639.

20. Willett WC, Reynolds RD, Cottrell-Hoehner S, Sampson L, Browne ML. Validation of a semi-quantitative food frequency questionnaire: comparison with a 1-year diet record. $J$ Am Diet Assoc. 1987; 87:43-47.

21. Willett WC. Nutritional Epidemiology. New York, NY: Oxford University Press; 1990.

22. US Dept of Agriculture Composition of Foods-Raw, Processed, and Prepared, 1963-1992. Washington, DC: US Dept of Agriculture; $1993 . \mathrm{Ag}-$ ricultural Handbook Series No. 8.

23. Giovannucci E, Stampfer MJ, Colditz GA, et al. Folate, methionine, and alcohol intake and risk of colorectal adenoma. J Natl Cancer Inst. 1993;85: 875-884.

24. Selhub J, Jacques PF, Wilson PWF, Rush D, Rosenberg IH. Vitamin status and intake as primary determinants of homocysteinemia in an elderly population. JAMA. 1993;270:2693-2698

25. Tucker KL, Mahnken B, Wilson PWF, Jacques P, Selhub J. Folic acid fortification of the food supply: potential benefits and risks for the elderly population. JAMA. 1996;276:1879-1885.

26. Stampfer MJ, Willett WC, Speizer FE, et al Test of the National Death Index. Am J Epidemiol. 1984:119:837-839

27. Willett WC, Stampfer MJ. Total energy intake: implications for epidemiologic analyses. Am J Epidemiol. 1986:124:17-27.

28. D'Agostino RB, Lee MLT, Belanger AJ, Cupples LA, Anderson K, Kannel WB. Relation of pooled logistic regression to time dependent Cox regression analysis: the Framingham Heart Study. Stat Med. 1990;9:1501-1515.

29. Nygard O, Nordrehaug JE, Refsum H, Ueland PM, Farstad M, Vollset SE. Plasma homocysteine levels and mortality in patients with coronary artery disease. N Engl J Med. 1997;337:230-236.

30. Durand P, Prost M, Blache D. Pro-thrombotic effects of a folic acid deficient diet in rat platelets and macrophages related to elevated homocysteine and decreased n-3 polyunsaturated fatty acids. Atherosclerosis. 1996;121:231-243.

31. Stampfer MJ, Hennekens CH, MansonJE, Colditz GA, Rosner B, Willett WC. Vitamin E consumption and the risk of coronary disease in women. N Engl J Med. 1993;328:1444-1449.

32. Rimm EB, Stampfer MJ, Ascherio A, Giovannucci E, Willett WC. Dietary folate, vitamin B6, and vitamin B12 intake and risk of CHD among a large population of men. Circulation. 1996;93:625. Abstract.

33. Tsai JC, Perrella MA, Yoshizumi M, et al. Promotion of vascular smooth muscle cell growth by homocysteine: a link to atherosclerosis. Proc Natl Acad Sci U S A. 1994;91:6369-6373.

34. Ueland PM, Refsum H, Brattstrom L. Plasma homocyst(e)ine and cardiovascular disease. In: Francis RBJ, ed. Atherosclerotic Cardiovascular Disease Hemostasis and Endothelial Function. New York, NY: Marcel Dekker Inc; 1992:183-236. 35. Stamler JS, Osborne JA, Jaraki O, et al. Adverse vascular effects of homocysteine are modulated by endothelium-derived relaxing factor and related oxides of nitrogen. J Clin Invest. 1993;91: 308-318.

36. Tawakol A, Omland T, Gerhard M, Wu JT, Creager MA. Hyperhomocyst(e)inemia is associated with impaired endothelium-dependent vasodilation in humans. Circulation. 1997;95:1119-1121. 37. Boers GH, Smals AG, Trijbels FJ, et al. Heterozygosity for homocystinuria in premature peripheral and cerebral occlusive arterial disease. $N E n g l$ J Med. 1985;313:709-715.

38. Malinow MR, Kang SS, Taylor LM, et al. Prevalence of hyperhomocyst(e)inemia in patients with peripheral arterial occlusive disease. Circulation. 1989;79:1180-1188

39. Kang SS, Wong PWK, Cook HY, Norusis M, Messer JV. Protein bound homocyst(e)ine-a possible risk factor for coronary artery disease. J Clin Invest. 1986;77:1482-1486.

40. Israelsson G, Brattstrom LE, Hultberg BL. Homocysteine and myocardial infarction. Atherosclerosis. 1988;71:227-233.

41. Arnesen E, Refsum H, Bonaa KH, et al. Serum total homocysteine and coronary heart disease. Int J Epidemiol. 1995;24:704-709.

42. Graham IM, Daly LE, Refsum HM, etal. Plasma homocysteine as a risk factor for vascular disease: the European Concerted Action Project. JAMA. 1997;277:1775-1781

43. Miller JW, Nadeau MR, Smith D, Selhub J. Vitamin B6 deficiency vs folate deficiency: comparison of responses to methionine loading in rats. $A m J$ Clin Nutr. 1994;59:1033-1039.

44. Bostom AG, Jacques PF, Nadeau MR, Williams RR, Ellison RC, Selhub J. Postmethionine load hyperhomocysteinemia in persons with normal fasting total plasma homocysteine: initial results from the NHLBI Family Heart Study. Atherosclerosis. 1995; 116:147-151.

45. Stampfer MJ, Rimm EB. Folate and cardiovascular disease: why we need a trial now. JAMA. 1996; 275:1929-1930.

46. Shaw S, Jayatilleke E, Herbert V, Colman N. Cleavage of folates during ethanol metabolism: role of acetaldehyde/xanthine oxidase-generated superoxide. Biochem J. 1989;257:277-280,

47. Herbert VD, Colman N. Folic acid and vitamin B-12. In: Shil ME, Young VR, eds. Modern Nutrition in Health and Disease. 7th ed. Philadelphia, $\mathrm{Pa}$ Lea \& Febiger; 1988:388-416.

48. Stampfer MJ, Colditz GA, Willett WC, Speizer $\mathrm{FE}$, Hennekens $\mathrm{CH}$. A prospective study of moderate alcohol consumption and the risk of coronary disease and stroke in women. $N$ Engl J Med. 1988; 319:267-273.

49. Pancharuniti N, Lewis CA, Sauberlich HE, et al. Plasma homocyst(e)ine, folate, and vitamin B-12 concentrations and risk for early-onset coronary artery disease. Am J Clin Nutr. 1994;59:940948.

50. Subar AF, Block G, James LD. Folate intake and food sources in the US population. Am J Clin Nutr. 1989;50:508-516.

51. Appel LJ. Folic acid fortification of food. JAMA. 1996;275:681-682

52. Bendich A. Folic acid and prevention of neural tube birth defects: critical assessment of FDA proposals to increase folic acid intakes. $J$ Nutr Educ. 1994;26:294-299. 